\title{
Heart Failure with Preserved Ejection Fraction: A Report about 64 Cases Followed at the Heart Institute of Abidjan
}

\author{
Fatoumata Traore*, Kamagaté Djenamba Bamba, Florent Koffi, Yves N'da Kouakou Ngoran, \\ Marie Paule Mottoh, Soya Esaie, Iklo Coulibaly
}

Heart Institute of Abidjan, Abidjan, Côte d'Ivoire

Email: *Traofa@yahoo.fr

How to cite this paper: Traore, F., Bamba, K.D., Koffi, F., Ngoran, Y.N.K., Mottoh, M.P., Esaie, S. and Coulibaly, I. (2017) Heart Failure with Preserved Ejection Fraction: A Report about 64 Cases Followed at the Heart Institute of Abidjan. World Journal of Cardiovascular Diseases, 7, 285-291. https://doi.org/10.4236/wjcd.2017.79026

Received: August 9, 2017

Accepted: September 19, 2017

Published: September 22, 2017

Copyright $\odot 2017$ by authors and Scientific Research Publishing Inc. This work is licensed under the Creative Commons Attribution International License (CC BY 4.0).

http://creativecommons.org/licenses/by/4.0/

\begin{abstract}
Objective: To describe the epidemiological and etiological features of heart failure with preserved ejection fraction in our context. Materials and Methods: This is a retrospective study that was carried out over a 12-month period, from 1 January 2015 to 31 December 2015, in the hospitalization department of the Heart Institute of Abidjan. It was about patients hospitalized for heart failure who had received a dose of NT-proBNP and who had had an electrocardiogram, and a Doppler echocardiography. Heart failure with preserved ejection fraction (HFPEF) was defined from the symptoms and signs of heart failure, the level of NT-proBNP and from echocardiography data based on the left ventricular ejection fraction (LVEF) $>50 \%$, the dilatation of the left atrium. The diastolic dysfunction of the left ventricle was assessed by the ratio E/E' > 13. We defined as heart failure with decreased ejection fraction (HFDEF) symptoms and signs of heart failure and left ventricular dysfunction LVEF $<40 \%$. A computer file was completed. It included epidemiological and etiological data. Results: The study involved sixty-four patients with heart failure with preserved ejection fraction out of 257 patients with heart failure that is a prevalence of $25 \%$. The mean age was $57.3 \pm 16$ years. There was a male predominance that is $52 \%$ of cases. Congestive heart failure was predominant in $67 \%$. NT-proBNP levels were $365 \mathrm{pg} / \mathrm{ml}$ on average. The average length of stay was $5.5 \pm 3.1$. Intra-hospital deaths were $4.6 \%$. The etiologies are dominated by high blood pressure in $85.9 \%$, followed by obesity in $28.1 \%$, then by ischemic heart disease in $4.6 \%$. There were no diabetic patients in this group. Conclusion: Heart failure with preserved ejection fraction is characterized in our regions by its occurrence in young male subjects. Congestive heart failure prevailed. The dominant etiology was high blood pressure.
\end{abstract}




\section{Keywords}

Epidemiology, Etiology, Heart Failure

\section{Introduction}

The concept of heart failure with preserved ejection fraction is relatively new. Historically, the diagnosis of heart failure was based primarily on clinical criteria, and patients described in the studies were likely to be a mixture of heart failure with altered ejection fraction and heart failure with preserved ejection fraction. The generalization of echocardiography in the 1980s and the need for standardization of diagnosis for inclusion in large therapeutic trials led to the exclusion from studies patients with preserved left ventricular ejection fraction. Studies have systematically focused on this population over the past 15 years, with a number of publications indexed in PubMed, from 13 in 2001 to 336 in 2014.

The profile of heart failure with preserved ejection fraction is known woman, in atrial fibrillation [1] [2] [3] [4]. However, in Africa, little work has been done on this type of heart failure and we do not have local data for this clinical entity. It is therefore appropriate to describe the epidemiological and etiological features of this condition in our context.

\section{Materials and Methods}

It is a comparative and descriptive retrospective study of records of patients hospitalized for heart failure in the medical department of the Heart Institute of Abidjan over a 12 month-period, from 1 January 2015 to 31 December 2015.

Heart failure with preserved ejection fraction (HFPEF) has been defined by the presence of symptoms and/or signs of heart failure (HF), elevation of NT proBNP, demonstration of left ventricular ejection fraction (LVEF) $>50 \%$ at the Simpson Biplane, dilation of the left atrium assessed at the Simpson biplane (4 cavities or 2 cavities) when the volume of the left atrium is $>32 \mathrm{ml} / \mathrm{m}^{2}$, left ventricular hypertrophy (LVH) assessed by the left ventricular mass index (LVMI) and the Relative parietal thickness (RPT)of the left ventricle, values systematically given by the ultrasound system, threshold values $110 \mathrm{~g} / \mathrm{m}^{2}$ in man and 95 $\mathrm{g} / \mathrm{m}^{2}$ in women. Thus, left ventricular hypertrophy (LVH) is said to be concentric when LVMI is high and the relative parietal thickness $(\mathrm{RPT})>0.45$. Left ventricular hypertrophy (LVH) is said eccentric when LVMI is high and relative parietal thickness $(\mathrm{RPT})<0.45$. We refer to concentric remodeling when LVMI is normal and RPT $>0.45$ ). Diastolic dysfunction was assessed by the ratio between the E wave at the pulsed Doppler of the mitral flow (synchronous with the protodiastolicrapid filling of the left ventricle) and the E' Wave at the tissue Doppler recording the spectral pulsed Doppler signal in the myocardial wall $>$ $\left(\mathrm{E} / \mathrm{E}^{\prime}>13\right)$. 
Heart failure with altered ejection fraction was defined by the presence of symptoms and/or signs of HF and LVEF $<40 \%$.

A computerized file was filled and the parameters studied were: epidemiological (age, gender, length of hospital stay, intra-hospital death), clinical (type of HF, NT-proBNP level and etiologies) and echocardiographic (size of left atrium (LA), LVH, E/E'13).

All patients with clinical, biological heart failure and with LVEF between 40 and $49 \%$ were not selected in our study.

The echocardiographic parameters were obtained using a VIVID 3 brand ultrasound system with a $2.5 \mathrm{MHZ}$ adult probe.

LVEF was measured by Teicholz or Simpson biplane (4 cavities, 2 cavities). The measurement of LVEF by Teicholz was used in the absence of segmental kinetic disorder.

Heart failure with preserved ejection fraction and heart failure with altered ejection fraction accounted for $64(25 \%) \ldots$ and 193 (75\%), respectively [5] [6] [7] [8] [9].

High blood pressure was accepted when systolic blood pressure (SBP) was $\geq 140 \mathrm{mmHg}$ and/or diastolic blood pressure (DBP) $\geq 90 \mathrm{mmHg}$.

Dilated cardiomyopathy was accepted according to the following criteria: dilation of the left ventricle (LV), overall kinetic disorder, homogeneous.

Valvular heart disease was accepted when there was an organ involvement.

Ischemic cardiopathy was accepted in case of a history of myocardial infarction that had benefited from coronary angiography or not, segmental contractility disorder in echocardiography.

Obesity was defined from the body mass index with a BMI $>30 \mathrm{~kg} / \mathrm{m}^{2}$.

Diabetes was defined from fasting blood glucose with a level $>1.26 \mathrm{~g} / \mathrm{l}$ and hbA1C $>7$.

All patients with clinical, biological heart failure with LVEF between $40 \%$ and $49 \%$ were not selected in our study.

The results are presented by standard averages and deviations or by percentages. Differences between patient groups according to LVEF were tested with the chi square test for categorical variables. The significance threshold was 0.05 .

\section{Results}

The study involved Sixty-four patients with heart failure with preserved ejection fraction out of 257 patients with heart failure that is a prevalence of $25 \%$. The mean age was $57.3 \pm 16$ years. There was a male predominance that is $52 \%$ of cases. Congestive heart failure was predominant in 67\%. NT-proBNP levels were $365 \mathrm{pg} / \mathrm{ml}$ on average. The average length of stay was $5.5 \pm 3.1$. Intra-hospital deaths were $4.6 \%$ (Table 1). Echocardiographic features of HFPEF were left ventricular ejection fraction $(52.6 \% \pm 8 \%)$, left ventricular mass $(114.5 \pm 31.3$ $\left.\mathrm{g} / \mathrm{m}^{2}\right)$, left atrial volume $\left(45 \pm 3.5 \mathrm{ml} / \mathrm{m}^{2}\right)$, E/E' $(19 \pm 4.2)$ (Table 2). The etiologies are dominated by high blood pressure in $85.9 \%$; Followed by obesity in 
$28.1 \%$ then by ischemic heart disease in $4.6 \%$. There were no diabetic patients in this group (Table 3 ).

Table 1. Epidemiological and clinical features of heart failures with preserved ejection fraction (HFPEF) and heart failures with altered ejection fraction (HFAEF).

\begin{tabular}{ccc}
\hline & IC-FEP (64) & IC-FEA (193) \\
Age & $57.3 \pm 16$ & $53.2 \pm 16.7$ \\
Sexe & 33 & 98 \\
M & 31 & 95 \\
F & 17 & 77 \\
Ancienneté de l'IC & & 7 \\
Type d'IC & 3 & 12 \\
OAP & 12 & 12 \\
ICG & 6 & 164 \\
ICD & 43 & $119 \pm 20.6$ \\
ICGLOBALE & $144 \pm 24.3$ & $84 \pm 18.7$ \\
PAS & $100 \pm 16.4$ & $15.6 \pm 9.2$ \\
PAD & $5.5 \pm 3.1$ & 16 \\
DMS & 3 &
\end{tabular}

Table 2. Echocardiographic features of HFPEF.

\begin{tabular}{cc}
\hline & Mensurations (moyenne) \\
\hline DTDVG & $49.3 \pm 1.51$ \\
DTSVG & $31.04 \pm 1.54$ \\
FEVG & $52.6 \pm 8$ \\
MVG & $114.5 \pm 31.3$ \\
VOG & $45.5 \pm 3.53$ \\
E/E' & $19.4 \pm 4.2$ \\
\hline
\end{tabular}

Table 3. Etiologic features of HFPEF.

\begin{tabular}{cccc}
\hline IC-FEP & & IC-FEA & $\mathrm{P}$ \\
\hline HTA & 85.9 & 2 & $<0.01$ \\
OBESITE & 28.1 & 1.9 & $<0.01$ \\
C ISCHEMI & 4.6 & 13.4 & $>0.05$ \\
CMD & 0 & 74 & $>0.05$ \\
VALVULOP & 0 & 9 & $<0.05$ \\
DIABET & 0 & 0 & \\
AUTRES & 0 & 2 & \\
\hline
\end{tabular}




\section{Discussion}

Heart failure is an increasingly common condition in our context. In our work, $25 \%$ of patients hospitalized for heart failure had heart failure with preserved ejection fraction (HFPEF). This prevalence is close to that found in the American studies, $24 \%$ to $55 \%$ [10] [11] and in African studies in particular that of Mouhamed Chérif in SENEGAL which found $28 \%$ and that of Addeji in NIGERIA which found 39.5\% [12] [13]. This prevalence may be higher in our context because some parameters of diastolic dysfunction such as the E/E' ratio between 8 and 13 had not been assessed, which would mean an increase in filling pressures when the left atrial volume is $>40 \mathrm{ml} / \mathrm{m}^{2}$ and/or associated with the difference between the pulsed Doppler of the pulmonary venous flow and the pulsed Doppler of the mitral flow $>30 \mathrm{~ms}$ and/or associated with systolic pulmonary arterial pressure (SPAP) $>35 \mathrm{mmhg}$.

The average age of patients with heart failure with preserved ejection fraction (HFPEF) was $53 \pm 16$ years. This is super imposable to that found by Mouhamed Chérif in Senegal 65.7\% $\pm 9.1 \%$ and Addeji in NIGERIA $52.3 \pm 16$ [12] [13]. Indeed, the mean age represents the average age of patients with heart failure in Africa which is proved by a study in Togo that found an average age of $52 \pm 16.7$ years and a Djiboutian study that found $55 \pm 12$ years [14] [15]. However, this average age is significantly lower than that found In the American and European series. In these studies, the average age was $79 \pm 7.6$ years and $71 \pm 12$ years respectively in the UNITED STATES and EUROPE [16] [17]. This difference could be related to life expectancy that is lower in our context but especially to the inaccessibility of the majority of the population to health structures. These cardiovascular risk factors are dominated by high blood pressure. In our study, high blood pressure is the most common etiology in patients with HFPEF that is 85.6\%. Masoudi in the United States and Lenzen in Europe found similar proportions $65 \%$ and 59\% respectively in their studies [16] [17]. In AFRICA, in particular in SENEGAL and NIGERIA, the studies found larger proportions of $96.1 \%$ and $82.9 \%$ respectively [12] [13]. This could be explained by the high prevalence of high blood pressure in our context and also the pathophysiological consequences of this disease on the left ventricular diastole. These consequences are disorders of the left ventricular relaxation and the ventricular and arterial rigidity. Obesity was found in patients with HFPEF in $28.1 \%$ in our study. This has been found in several studies. This may be explained by the fact that obesity is frequently associated with high blood pressure and thus with left ventricular hypertrophy, which is the cause of abnormal relaxation or even diastolic dysfunction of the left ventricle [18] [19].

Ischemic heart disease was found in $4.6 \%$ of patients with HFPEF in our study. Our figures are much lower than those of the literature. A Chinese study found 29.3\% [20] and an American study found 21\% [16]. This could be explained by the inadequacy of the technical platform and the medical staff for the systematic performance of coronary angiography. 
We did not find diabetics in our study, whereas in the work of Nurcan [21] and Mouhamed Cherif [12], the prevalence of diabetes was $42.3 \%$ and $45 \%$, respectively. And in the study of Tribouilly, diabetes was a poor prognostic factor in patients with HFPEF. Its presence was associated with a 5-year survival of $32 \%$ and an increase in mortality of $60 \%$ compared with the group of non-diabetic patients [22].

\section{Limitations of the Study}

The limitation of our study is mainly the unavailability of certain parameters of echocardiographies, namely the duration of the A wave at the pulsed Doppler of the pulmonary venous flow and the duration of the A wave at the pulsed Doppler of the mitral flow because they have not been set by our ultrasound system and because of the lack of experienced echocardiographers.

The current definition of heart failure with preserved ejection fraction (HFPEF) has limited the number of patients.

\section{Conclusion}

Heart failure with preserved ejection fraction is characterized in our regions by its frequent occurrence in the congestive mode, in young hypertensive men. Complications of high blood pressure occur early and severe in the African black subject. We will insist on prevention which must be based on early screening and efficient management of this main cardiovascular risk factor in Africa.

\section{References}

[1] Teo, L.Y., Chan, L.L. and Lam, C.S. (2016) Heart Failure with Preserved Ejection Fraction in Hypertension. Current Opinion in Cardiology, 31, 410-416. https://doi.org/10.1097/HCO.0000000000000292

[2] Millikovik, L.V. and Spiroska, V. (2015) Heart Failure with Preserved Ejection Fraction-Concept Pathophysiology, Diagnosis and Challenges for Treatement. Open Access Macedonian Journal of Medical Sciences, 3, 521-527. https://doi.org/10.3889/oamjms.2015.087

[3] Owan, T.E. and Herges, R.M. (2006) Trends in Prevalence and Outcome of Heart Failure with Preserved Ejection Fraction. The New England Journal of Medicine, 355, 251-259.

[4] Tu, J.V. and Lee, D.S. (2006) Outcome of Heart Failure with Preserved Ejection Fraction in a Population-Based Study. The New England Journal of Medicine, 355, 260-269.

[5] McMurray, J.J. and Adamopoulos, S. (2012) ESC Guidelines for the Diagnosis and Treatment of Acute and Chronic Heart Failure 2012: The Task Force for the Diagnosis and Treatment of Acute and Chronic Heart Failure 2012 of the European Society of Cardiology. European Journal of Heart Failure, 14, 149-156.

[6] Paulus, W.J., Tschope, C. and Sanderson, J.E. (2007) How to Diagnose Diastolic Heart Failure: A Consensus Statement on the Diagnosis of Heart Failure with Normal Left Ventricular Ejection Fraction by the Heart Failure and Echocardiography Associations of the European Society of Cardiology. European 
Heart Journal, 28, 2539-2550.

[7] Heart Failure: An Update. Clinical Pharmacology \& Therapeutics 2013.

[8] Rodeheffer, R.J. and Jacobsen, S.J. (2004) Plasma Brain Natriuretic Peptide to Detect Preclinical Ventricular Systolic or Diastolic Dysfonction: A Community-Based Study. Circulation, 109, 3176-3181.

[9] Aurigemma, G.P., Gottdiener, J.S., Shemanski, L., Gardin, J. and Kitzman, D. (2001) Prédictive Value of Systolic and Diastolic Function for Incident Congestive Heart Failure in the Elderly: The Cardiovascular Health Study. Journal of the American College of Cardiology, 37, 1042-1048.

[10] Malki, Q., Sharma, N.D., Afzal, A., et al. (2002) Clinical Presentation, Hospital Length of Stay, and Readmission Rate in Patients with Heart Failure with Preserved and Decreased Left Ventricular Systolic Function. Clinical Cardiology, 25, 149-152. https://doi.org/10.1002/clc.4960250404

[11] Vaccarino, V., Gahbauer, E., Kasl, S.V., et al. (2002) Differences between African Americans and Whites in the Outcome of Heart Failure: Evidence for a Greater Functional Decline in African Americans. American Heart Journal, 143, 1058-1067. https://doi.org/10.1067/mhj.2002.122123

[12] Mboup, M.C., Dia, K. and Fall, P.D. (2013) Heart Failure Preserved Ejection Fraction Sub-Saharan Africa about 32 Cases. The Pan African Medical Journal, 16, 100. https://doi.org/10.11604/pamj.2013.16.100.2323

[13] Adebayo, A.K., Adedebiyi, A.A., Oladapo, O.O., et al. (2009) Characterisation of Heart Failurewith Normal Ejection Fraction in a Tertiary Hospital in Nigeria. BMR Cardiovascular Disorders, 9, 52.

[14] Pio, M., Afassinou, Y., Pessinaba, S., et al. (2014) Epidemiology and Etiologies of Heart Failure in Lome. The Pan African Medical Journal, 18, 183.

[15] Massouré, P.L. (2013) Heart Failure in Adults in Djibouti: the Prospect of an Epidemiological Transition. Medecine et santé tropicale, 23, 2.

[16] Masoudi, F.A., et al. (2003) Gender, Age and Heart Failure with Preserved LV Systolicfunction. Journal of the American College of Cardiology, 41, 217-223.

[17] Lenzen, M.J., et al. (2004) Differences between with Patients Has Preserved and Depressed LV Function: A Report from the Euro Heart Failure Survey. European Heart Journal, 25, 1214-1220.

[18] Ennezat, P.V., Le Jemtel, T.H., Logeart, D., et al. (2012) Preserved Ejection Fraction Heart Failure: A Disease of System? The Journal of Medicine Internal, 3, 370-380.

[19] Roncalli, J., Pathak, A. and Galinier, M. (2007) Obesity and Heart Failure. MT Cardio, 3, 178-186.

[20] Hai, J.J., Chan, P.H., Huang, D., et al. (2016) Clinical Characteristics, Management, and Outcomes of Hospitalized Heart Failure in a Chinese Population-The Hong Kong Heart Failure Registry. Journal of Cardiac Failure, 22, 600-608.

[21] Nurcan, I., Hoffman, M., Moore, R.H., Easley, K. and Jacobson, T.A. (2006) Comparison of African-American Patients with Systolic Heart Failure versus Preserved Ejection Fraction. American Journal of Cardiology, 98, 806-808.

[22] Tribouilly, C., Rusinaru, D., Mahjoub, H., et al. (2008) Prognostic Impact of Diabetes Mellitus in Patients with Heart Failure and Preserved Ejection Fraction: A Prospective Five-Year Study. Heart, 94, 1450-1455. https://doi.org/10.1136/hrt.2007.128769 
Submit or recommend next manuscript to SCIRP and we will provide best service for you:

Accepting pre-submission inquiries through Email, Facebook, LinkedIn, Twitter, etc. A wide selection of journals (inclusive of 9 subjects, more than 200 journals)

Providing 24-hour high-quality service

User-friendly online submission system

Fair and swift peer-review system

Efficient typesetting and proofreading procedure

Display of the result of downloads and visits, as well as the number of cited articles Maximum dissemination of your research work

Submit your manuscript at: http://papersubmission.scirp.org/

Or contact wicd@scirp.org 